\title{
O problema do estilo na obra de José Mojica Marins
}

\author{
Rodrigo Carreiro
}

Resumo: Mais conhecido cineasta brasileiro de horror, José Mojica Marins tem uma obra vasta, na qual transitou por outros gêneros fílmicos, como o western e o sexo explícito. Ele trabalhou dentro de modos de produção distintos, usou diversas tecnologias e lidou com mudanças profundas no círculo de colaboradores. Tudo isso teve como consequência certa heterogeneidade temática, visual e sonora nos filmes que ele dirigiu, tornando mais difícil a tarefa de rastrear uma assinatura estilística em sua obra. Apesar disso, é possível afirmar que seus filmes têm um estilo próprio. Este ensaio procura identificar padrões recorrentes de forma e conteúdo na obra de Mojica, tentando explicá-los através do exame dos contextos socioculturais, tecnológicos, econômicos e políticos que afetaram o trabalho e a vida pessoal do cineasta.

Palavras-chave: cinema brasileiro; gênero fílmico; estilo; José Mojica Marins

Abstract: The problem of style in the work of José Mojica Marins - Brazil's most well-known horror filmmaker, Jose Mojica Marins has a vast collection of works that include genres such as Westerns and sexually explicit films. He has employed different modes of production, used various technologies, and dealt with profound changes in his circle of collaborators. All this has led to a certain degree of thematic, visual and sound heterogeneity in the films he has directed, making it harder to trace a stylistic signature in his work. Nevertheless, his films clearly have a style of their own. This essay seeks to identify recurring patterns of form and content in Mojica's work, trying to explain them by examining the socio-cultural, technological, economic and political contexts that affect the filmmaker's professional and private life.

Keywords: brazilian cinema; film genres; style; José Mojica Marins

\section{Introdução}

José Mojica Marins é um dos mais conhecidos realizadores do cinema de horror na América Latina. Ele se tornou famoso internacionalmente devido ao sucesso do carismático e soturno personagem Zé do Caixão, que aparece em alguns dos filmes mais 
interessantes que realizou. Sua obra consiste de 24 longas-metragens, duas dezenas de curtas (vários deles desaparecidos, de modo que não é possível saber o número exato) e um média-metragem, realizados a partir de 1953. Além do horror, Mojica também transitou por outros gêneros fílmicos, como o western, o melodrama e o sexo explícito (nos quais sempre flertou com elementos oriundos da iconografia do horror). Tudo isso nos leva a uma questão sobre a qual este texto refletirá: é possível falar de estilo quando se menciona os filmes de José Mojica Marins?

O termo estilo é traiçoeiro. David Bordwell (2009, p. 57) afirma que, apesar de os cinéfilos utilizarem a palavra com frequência, a pesquisa rigorosa sobre o estilo no cinema tem sido negligenciada há muitas décadas, ao contrário do que tem acontecido nas letras ou nas belas-artes, vertentes da atividade artística em que a estilística ocupa lugar privilegiado. Uma das razões mais fortes para esse desprezo, por parte dos pesquisadores do cinema, é exatamente o caráter escorregadio do termo. Afinal de contas, o que se deve tomar por estilo?

Antoine Compagnon (2010, p. 166) enxerga significados ambíguos e contraditórios no uso cotidiano que se faz da palavra. Estilo pode significar a norma (modelo a ser imitado) ou um desvio da norma (variação formal que distingue o texto mais sofisticado de outro inferior); estilo pode ser ornamento (enfeite retórico, às vezes desnecessário) ou sintoma (grupo de características que permitem a identificação posterior de uma obra produzida num determinado período histórico).

Dependendo do contexto em que for utilizado, o termo estilo pode significar coisas distintas, até mesmo opostas. No cinema, essa ambiguidade se afirma principalmente na tensão existente entre o estilo de um grupo, gênero ou período histórico específico e o estilo individual de um cineasta. Mencione o expressionismo alemão ou o western, por exemplo, e é possível discorrer sobre estilos característicos de cada expressão fílmica. Mas também se pode falar do estilo de um diretor. Quando mencionamos o estilo de Alfred Hitchcock ou Quentin Tarantino, estamos nos referindo a certo repertório de técnicas e/ou temas que esses diretores empregam de maneira recorrente, em filmes diferentes. Nesse sentido, também se pode procurar a assinatura estilística de um diretor que trabalha dentro de um gênero, equilibrando um estilo coletivo e outro individual dentro da mesma obra - como é o caso de Mojica.

Antes de proceder à análise dos filmes e tentar identificar onde estaria o estilo pessoal de José Mojica Marins, é preciso aproximar-se de uma definição estável do termo. Estilo seria, então, um conjunto de padrões de forma e conteúdo recorrentes na obra de um artista ou grupo. A assinatura estilística daria conta do estilo individual de um diretor. Padrões recorrentes, é claro, só podem ser encontrados através da análise dos recursos estilísticos orquestrados pelo cineasta (ou grupo de cineastas) para contar histórias. Mas de onde vêm esses recursos, e por qual (ou quais) motivo(s) um diretor de cinema os seleciona, e não a outros? 
A assinatura estilística nasce das soluções encontradas pelo cineasta para resolver problemas de representação com os quais depara no dia a dia. Cada cineasta opera suas próprias escolhas. Quando constituem um padrão recorrente, elas definem o seu estilo. Para Bordwell (2009, p. 320) o processo de contar uma história num meio audiovisual consiste, grosso modo, numa sucessão constante de problemas de representação, que o diretor soluciona fazendo escolhas com base em um repertório disponível (e que o diretor pode revisar, sofisticar ou sintetizar). Cada problema pode ser resolvido seguindo-se uma série de soluções possíveis, entre as quais o artista deve escolher uma (ou mais de uma). Esse é o paradigma do problema/solução.

Trata-se da adaptação para o cinema do conceito de esquema (GOMBRICH, 2007), segundo o qual os artistas não criam a partir do nada, mas trabalham dentro de uma tradição que dispõe de um repertório de recursos e normas de estilo. Cada artista ajusta os esquemas disponíveis a novas possibilidades oferecidas pelos contextos socioculturais, econômicos, tecnológicos e políticos em que trabalha. O estilo, então, pode ser compreendido como o resultado autoral de um conjunto de escolhas.

O problema do estilo, conforme sintetizado por Bordwell, encontra ressonância concreta em cineastas como José Mojica Marins. Além de ter realizado filmes de gêneros diferentes, Mojica trabalhou dentro de modos de produção distintos, com tecnologias distintas (filmes em 35, dezesseis e oito milímetros e fitas de vídeo), lidou com mudanças profundas no círculo de colaboradores criativos mais próximos (produtores, roteiristas, fotógrafos e montadores variaram), sofreu com os cortes determinados pela censura oficial que existia no Brasil nas décadas de 1960 e 1970. Tudo isso teve como consequência certa heterogeneidade temática, visual e sonora nos filmes que ele dirigiu, tornando mais difícil a tarefa de rastrear uma assinatura estilística em sua obra.

Levando tudo isso em consideração, é possível afirmar que os filmes de José Mojica Marins denotam um estilo? Quais são os padrões recorrentes de forma e conteúdo que se pode rastrear nos trabalhos dele? Que contextos socioculturais, tecnológicos, econômicos e políticos explicam a existência desses padrões? Como os sistemas de produção de baixo orçamento, com os quais ele operou na maior parte da carreira, determinaram ou influenciaram a constituição dos padrões? E de que modo os filmes assinados por Mojica se relacionam com outros ciclos internacionais de cinema popular nascidos dentro de sistemas de produção semelhantes?

Responder a essas perguntas é o objetivo principal deste texto. Para alcançá-lo, tentaremos seguir a metodologia de análise estilística proposta por Bordwell e inspirada em Gombrich. Esse procedimento metodológico consiste em realizar uma análise cuidadosa dos filmes que Mojica dirigiu, combinando-a com uma reconstituição da trajetória pessoal e profissional do diretor, sem esquecer de concretizar a necessária análise dos contextos históricos que o circundavam durante a produção dos filmes. Tentaremos, desse modo, não apenas identificar os padrões recorrentes de estilo existentes na obra de Mojica, mas também explicar a origem de cada padrão e mapear os desvios e aproximações desses padrões. 


\section{Padrões de estilo na trajetória de Mojica}

Uma revisão atenta dos filmes dirigidos por Mojica revela um repertório consistente de padrões de forma e conteúdo que reaparecem, de modo recorrente, nos filmes que ele dirigiu, às vezes com alterações que envolvem variados graus de ênfase. A maior parte desses padrões de estilo surge com destaque nas obras que pertencem ou flertam com o gênero horror - algo que nos parece natural, uma vez que o horror é o gênero fílmico no qual Mojica mais atuou, e é nele que se sente mais à vontade. A seguir, relacionamos alguns desses padrões recorrentes, para em seguida proceder à análise dos contextos socioculturais, biográficos, tecnológicos, econômicos e políticos que podem ter levado Mojica a adotá-los.

Os principais padrões observados nos filmes são os seguintes: close-ups do rosto dos atores; planos detalhes de olhos; uso intenso do zoom; cenografia com pequeno grau de realismo, muitas vezes improvisada; sincretismo religioso, com iconografia oriunda de diversas religiões, incluindo cristianismo, candomblé e espiritismo; elementos visuais típicos do circo; tendência ao uso de um discurso que mistura tom messiânico com filosofia de almanaque; imagens de ultraviolência, incluindo estupros e canibalismo encenados com insistência; influências de histórias em quadrinhos, em particular das revistas de horror populares no Brasil dos anos 1950 e 1960 (uso de um narrador que se dirige diretamente ao espectador, prólogo sem conexão narrativa com a trama do filme, muitos close-ups); presença de pesadelos, tanto no sentido literal (personagens sonhando) quanto no figurado (atmosfera onírica); iconografia que mistura a influência gótica do imaginário internacional do cinema de horror com imagens oriundas da cultura brasileira; presença de cemitérios, caixões, cruzes, cenas de tempestade e animais exóticos (aranhas, cobras, ratos); tendência acentuada ao voyeurismo, com cenas que envolvem personagens assistindo (muitas vezes escondidos) a episódios de tortura, violência e/ou sexo; desprezo pelo som direto, com predomínio massivo de diálogos dublados; e utilização de músicas preexistentes de estilos diversos, indo da música popular à erudita.

A ferramenta mais característica do trabalho de Mojica consiste no uso frequente de close-ups de rostos. É importante observar que o uso que o brasileiro dá ao recurso se aproxima bastante do modo como filmava outro diretor de filmes de horror oriundo de um ciclo de produção popular: o italiano Mario Bava, um dos primeiros diretores europeus dos anos 1960 a ampliar o uso do close-up de rostos. Essa tendência ao uso amplo desse recurso atingiria o ápice em meados dos anos 1960, no trabalho de Sergio Leone e no ciclo de westerns spaghetti como um todo.

Mojica sempre afirmou que não conhecia o trabalho de Mario Bava (PRIMATI in PUPPO, 2007) ao começar a filmar. Tanto Mojica quanto Bava seguiam, no entanto, uma escola de encenação cinematográfica que usava o manejo da câmera como recurso para hiperdramatizar a narrativa. Essa escola tinha representantes ilustres na história 
do cinema: Sergei Eisenstein, Alfred Hitchcock e Carl Dreyer, por exemplo, concebiam desde os anos 1920 o close-up como um estudo pictórico da face humana, extraindo desse uso não uma informação objetiva, mas um efeito emocional: "a essência está em filmar expressivamente. Devemos [...] usar o limite da forma simples e econômica que expressa o que precisamos" (EISENSTEIN, 2002, p. 137).

Outra razão que pode ser apontada para o uso amplo de close-ups foi o aparecimento da televisão. A partir do final dos anos 1940, a utilização de close-ups aumentou gradativamente (SALT, 2009, p. 247). Seriados de TV recorriam com frequência ao close-up do rosto dos atores para permitir que o público acompanhasse a modulação emocional do enredo com mais facilidade - verificar o grau de emoção irradiado por um rosto em planos gerais ou médios, na tela pequena de um aparelho de televisão, era bastante difícil, de forma que os diretores começaram a inserir close-ups de reação dos atores nos momentos mais dramaticamente significativos.

Além disso, havia a influência dos quadrinhos de horror. Mojica era, desde os oito anos de idade, um leitor fanático de revistas em quadrinhos. Ele chegou a montar uma pequena biblioteca em casa, trocando moedas ou brinquedos com outras crianças para deixá-las ler as revistas que comprava, quando tinha entre onze e catorze anos (BARCINSKI; FINOTTI, 1998, p. 42). Mojica possuía predileção pelos quadrinhos de horror e lia regularmente títulos como as revistas Terror Negro, Gato Preto, O Mundo das Sombras e Sexta-Feira 13, todas populares nos anos 1950 (CÁNEPA, 2008, p. 91). Ele incorporou essa influência ao seu cinema, em vários níveis: no uso de iluminação low key, com fortes contrastes entre preto e branco e ausência de meios-tons; no insistente recurso do prólogo, em que um narrador sem relação direta com a trama introduz a história ou o tema do filme; e, claro, no uso do close-up de rostos, muito utilizado nos quadrinhos brasileiros de horror para que os desenhistas pudessem enfatizar a expressão de ameaça dos vilões e de medo das vítimas (REIS, 2002, p. 187).

Para efeito de comparação, Barry Salt (2009, p. 281) contou os tipos de planos em uma amostragem de vinte dos 151 longas-metragens produzidos nos Estados Unidos em 1959 e chegou a um percentual de 34,38 por cento de close-ups. Ou seja, um a cada três planos em filmes norte-americanos da época são close-ups. O primeiro filme de Mojica, À meia-noite levarei sua alma (1964), enquadra rostos em close-up durante 182 dos 379 planos, ou em 48,02 por cento do total - praticamente um plano em close-up de rosto para cada dois, portanto bem acima da média de Hollywood. Sergio Leone, que dirigiu seu primeiro western spaghetti no mesmo ano e ficaria depois conhecido como o cineasta que mais utilizou close-ups de rostos nos anos 1960, fez filmes em que a relação estatística entre o número de close-ups e o total de planos ficava entre cinquenta por cento e 55 por cento - um percentual bem próximo ao encontrado nos filmes de Mojica. A obra de Leone apresentava influência direta de Mario Bava. 
Os planos em close-up de olhos também se enquadram na tendência de Mojica a uma encenação que hiperdramatiza o enredo dos filmes. O próprio Mojica, contudo, atribuía o fascínio que sentia pelos olhos humanos a um episódio ocorrido na infância. Em depoimento a Eugênio Puppo e Arthur Autran (MOJICA in PUPPO, 2007), ele lembra ter assistido, certa vez, a um número de circo em que o atirador de facas errou o alvo e acertou de raspão a testa do pai dele, então atuando como assistente daquele número. $\mathrm{O}$ erro do atirador de facas fez o sangue escorrer por entre os olhos durante vários minutos. A visão sangrenta acompanhou Mojica pelo resto da vida. Esse foi um de vários episódios da infância do cineasta que determinaram uma influência indireta na constituição de padrões recorrentes de estilo em seus filmes, como veremos adiante.

O uso abundante das lentes zoom é outro recurso que Mojica compartilhou com Bava e outros diretores de filmes populares italianos. A semelhança, nesse caso, pode ser debitada ao modo de produção, muito semelhante em Cinecittà (onde Bava se formou como cineasta) e na região da Boca do Lixo ${ }^{1}$, berço do movimento do cinema marginal no Brasil e local onde Mojica desenvolveu seu estilo. As lentes zoom têm distância focal variável e permitem que o operador de câmera modifique o enquadramento de uma tomada, passando de um plano geral para um detalhe (ou vice-versa) sem efetuar cortes, o que acelera - e, por conseguinte, barateia - o tempo de filmagem. Apesar de as lentes zoom existirem para câmeras de 35 milímetros desde 1932, elas só começaram a ser utilizadas com mais frequência no cinema durante os anos 1960, e ganharam popularidade nos ciclos de produção populares, como o italiano e o brasileiro. Nos filmes de Hollywood o zoom era (e ainda é) evitado, porque a imagem obtida tem menos nitidez do que a conseguida com lentes de distância focal fixa.

A influência do circo pode ser debitada à proximidade de Mojica com o ambiente circense, já que seu pai trabalhava ocasionalmente como toureiro nesses espetáculos itinerantes. Desde o nascimento em 13 de março de 1936, o futuro cineasta tinha contato com membros de comunidades circenses que circulavam pelo Brasil - formadas principalmente por imigrantes europeus, muitos de origem cigana - apresentando espetáculos populares (MOJICA in PUPPO, 2007). A convivência com trupes de circo e ciganos pode ter sido importante para a caracterização de alguns personagens da obra futura de Mojica, como a bruxa que introduz À meia-noite levarei sua alma, o professor Oaxiac Odez de O estranho mundo de Zé do Caixão (1968) e vários personagens do filme metalinguístico $O$ despertar da besta (1969).

O interesse de Mojica pelo cinema também foi despertado, indiretamente, pela convivência com o circo. Eugênio Puppo e Arthur Autran relatam que Mojica, então com

1 Região composta de dezesseis quarteirões, no centro de São Paulo, e que se tornou um polo cinematográfico a partir dos anos 1920, quando empresas de Hollywood como Fox, Paramount e MGM instalaram lá as filiais brasileiras de seus estúdios. Nos anos 1960, já decadente e ocupada por prostíbulos, a Boca do Lixo sediou a eclosão do movimento do cinema marginal brasileiro, e cineastas como Ozualdo Candeias, Rogério Sganzerla e Luiz Sérgio Person, além de Mojica, abriram lá escritórios onde grande parte da produção cinematográfica brasileira dos anos 1970 foi concebida. 
dois anos, foi autorizado a passar um final de semana num acampamento de circo, com o pai, mas, por causa da cheia de um rio da região, a criança só voltou para casa dois dias depois do que havia sido combinado. A mãe dele, Carmen Marins, ficou assustada e pressionou o marido a parar de viajar e fixar residência em São Paulo (MOJICA in PUPPO, 2007). Foi assim que, em 1938, os Marins passaram a morar num casarão na região de Vila Anastácio, onde Antônio conseguiu emprego como gerente do Cine Santo Estevão, uma sala de projeção popular, de seiscentos lugares, que exibia, nas noites de terças e quintas, melodramas, westerns, seriados classe B e filmes de horror (BARCINSKI; FINOTTI, 1998, p. 34).

Foi no Cine Santo Estevão que Mojica construiu um repertório cinematográfico. Além de ter visto lá os filmes de monstro realizados pelos estúdios Universal nos anos 1930, Mojica desenvolveu o hábito de observar não apenas os filmes, mas também o comportamento das pessoas na plateia. Ele gostava de ficar na cabine de projeção, de onde podia tanto olhar para a tela quanto para as cadeiras de madeira onde o público se acomodava. Prestava atenção nos casais de namorado e lembrou, anos mais tarde, de ter percebido o dentista do bairro fazendo sexo com uma mulher casada dentro do cinema (MOJICA in PUPPO, 2007). Esse olhar voyeur também se constituiria como um padrão recorrente: nos filmes que dirigiu, uma situação dramática que se repete com frequência consiste em mostrar um personagem observando (muitas vezes escondido) uma cena que envolve sexo, tortura e sadismo. Esta noite encarnarei no teu cadáver (1965), A estranha hospedaria dos prazeres (1977), Perversão (1978) e Encarnação do demônio (2008) são alguns dos longas-metragens em que esse padrão se repete.

O cinema também era frequentado por imigrantes de vários países e classes sociais. Essa mistura de raças e culturas daria a Mojica uma visão de mundo em que conflitos de ordem social estavam em segundo plano, o que o ajudou a construir um cinema sem preocupações realistas. Por isso, em filmes cuja ambientação pedia realismo, Mojica enfrentou problemas com a crítica brasileira, em especial quando preferiu ambientar tramas no contexto da alta burguesia paulistana. Foi o que ocorreu com Perversão (1978), cujo enredo focaliza os desmandos de um sádico comendador italiano na alta sociedade local. Não foi difícil para os críticos notarem que a cenografia de Mojica incluía incongruências e erros de caracterização, como encenar uma festa para a alta sociedade com garçons servindo uísque em copos de requeijão e canapés em bandejas de papelão.

O jogo entre o popular e o erudito se manifesta nos filmes de Mojica de dois modos. Em primeiro lugar, através da tentativa (algo rasteira) de expressar uma filosofia de vida através de diálogos e monólogos, recitados em tom solene e messiânico. Nesse sentido, o personagem mais emblemático da obra de Mojica é o protagonista homônimo de Finis hominis (1971), longa-metragem simbolista em que um homem nu sai do mar e leva toda uma cidade a acreditar que tem poderes divinos. Diversos filmes de Mojica são abertos com prólogos desconectados da trama, em que o cineasta recita trechos filosóficos, ilustrados por imagens e sons que constituem, em si mesmos, mais um padrão recorrente: 
raios e trovões, rosto de pessoas gritando, animais peçonhentos (como cobras, aranhas e lagartos), cemitérios, lápides, cruzes. Esse tipo de prólogo aparece em $O$ estranho mundo de Zé do Caixão, Finis hominis, A estranha hospedaria dos prazeres, entre outros.

Algumas das imagens que ilustram esses prólogos ressurgem ao longo da obra do cineasta, incorporadas aos enredos dos filmes. Aranhas-caranguejeiras e cobras, por exemplo, são frequentemente mostradas passeando sobre os corpos desnudos de atrizes, em cenas voyeurísticas de vários filmes de Mojica, como Esta noite encarnarei no teu cadáver, Trilogia do terror e Encarnação do demônio. Muitas cenas cruciais - inclusive um longo plano sequência de quatro minutos em À meia-noite levarei sua alma - ocorrem durante tempestades. Imagens de cemitérios, túmulos e caixões também aparecem de maneira recorrente em praticamente todos os filmes dele.

Nesse último caso, mais um episódio ocorrido na infância do diretor (e reencenado de forma ficcional no filme Trilogia do terror, de 1968) influenciou a formação de seu imaginário. Durante o velório de Manoel, um quitandeiro que vendia batatas e tomates à família Marins, nos anos 1940, Mojica viu o suposto defunto levantar do caixão. O homem, na verdade, sofria de catalepsia. O episódio traumatizou Mojica (MOJICA in PUPPO, 2007). Nos seus filmes, ele bolou diversas cenas envolvendo pessoas levantando de caixões, como ocorre em À meia-noite levarei sua alma, Esta noite encarnarei no teu cadáver e Encarnação do demônio. No longa-metragem A estranha hospedaria dos prazeres, o protagonista é ressuscitado durante o prólogo, durante um ritual de candomblé.

Mais um aspecto recorrente nos filmes de Mojica que parece ter relação direta com sua infância é o sincretismo religioso. Nesse sentido, é possível afirmar que o caldeirão de raças da Vila Anastácio funcionou como um microcosmo do Brasil, país em que a maior parte da população pratica determinada religião (em particular o catolicismo) sem deixar de flertar com outras, como o candomblé e o espiritismo.

Nos filmes de Mojica, e em especial aqueles que contam com a presença do personagem Zé do Caixão, aparecem elementos de diversas religiões. Em Trilogia do terror, por exemplo, Mojica filmou uma cerimônia de candomblé, incluindo homens comendo vidro e uma galinha sendo morta a dentadas em frente à câmera. Cerimônia parecida aparece em Encarnação do demônio, enquanto em À meia-noite levarei sua alma o protagonista destrói na rua um despacho de macumba. A figura sombria de Zé do Caixão, aliás, encapsula de maneira eficiente esse padrão de estilo:

Enquanto na Itália, México e outros países fora do eixo Estados Unidos/Inglaterra praticamente se reproduziam as características do horror anglo-saxão, Mojica os reinterpretava para o universo de nossa cultura popular de pombas-gira, livros de São Cipriano, encruzilhadas, macumba, caipiras, coronéis e literatura de cordel. O próprio Zé do Caixão é uma representação desse sincretismo, uma mistura de Exu - a quem certamente remete com a sua postura desafiadora e anárquica - com conde Drácula, com sua barba cerrada, capa preta, cartola e unhas compridas. Poderíamos até afirmar que se o Diabo existisse, no Brasil se vestiria daquele modo (REIS, 2002, p. 187). 
De fato, é possível afirmar que Mojica se especializou em mesclar elementos da cultura brasileira com a iconografia do horror internacional. Ao lado dos elementos tipicamente brasileiros, podemos ver nos filmes dele cemitérios repletos de lápides construídas no estilo gótico, incomuns nos cemitérios do Brasil, mas vistas regularmente nos filmes da produtora inglesa Hammer (exibidos em São Paulo no começo da década de 1960). O uso de gelo-seco para criar névoa também é um procedimento normal no horror inglês das décadas de 1950 e 1960 e foi adotado sem questionamento nos filmes de horror de Mojica, embora o nevoeiro seja um elemento climático incomum no Brasil.

Um aspecto em que não se pode negar a originalidade do diretor é a questão da representação da violência. Nos primeiros longas-metragens que realizou, Mojica não se furtou a criar imagens explícitas de ultraviolência, raras para aquela época. Em À meianoite levarei sua alma, Zé do Caixão ataca dois homens na cidade, rasgando a face de um deles com espinhos e arrancando a mão de outro com uma garrafa - e as duas cenas são mostradas em close-up. As cenas de canibalismo de $O$ estranho mundo de Zé do Caixão e Encarnação do demônio, os estupros encenados em Trilogia do terror e Perversão e os diversos episódios de tortura envolvendo animais peçonhentos, do mesmo modo, também constituem padrões recorrentes na obra do diretor:

Mojica foi um dos pioneiros mundiais na produção de filmes de horror explícito, sendo, hoje, considerado um dos "pioneiros" do gore, juntamente o com os cineastas [...] Hershel Gordon Lewis e Nobuo Nakagawa (CÁNEPA, 2008, p. 137).

A questão da representação realística da violência é um ponto em que, como nos casos do uso abundante do zoom e na profusão de close-ups de rosto, aproxima bastante o trabalho de José Mojica Marins aos filmes de baixo orçamento realizados na Itália, no princípio dos anos 1960. Mas havia ainda outra característica marcante que tornou muito parecidos os longas-metragens de Mojica e os filmes de Cinecittà: o uso intenso da dublagem, padrão mais recorrente e reconhecível da obra do diretor brasileiro, no que se refere ao uso do som.

Mojica, assim como todos os diretores que comandaram produções populares no cinema italiano dos anos 1960, não usou som direto até os anos 2000. Assim como no caso dos cineastas italianos - inclusive Mario Bava -, essa foi uma solução estilística predeterminada pelo sistema de produção dentro do qual os cineastas atuavam.

O motivo principal para o descarte do som direto, no cinema popular brasileiro, foi o mesmo do ciclo de baixo orçamento da Itália: financeiro. Gravadores de som sincronizados com películas eram mais caros do que Mojica podia pagar. Na Itália, os diretores vinculados a Cinecittà estavam acostumados a trabalhar com a dublagem. Essa prática era comum no país europeu desde a década de 1940.

No Brasil, a prática da dublagem era uma imposição orçamentária, e não apenas às produções independentes, como aquelas levadas a cabo por Mojica. Nos anos 1950, 
qualquer longa-metragem filmado fora das dependências da Vera $\mathrm{Cruz}^{2}$ precisava recorrer ao som pós-sincronizado. O orçamento minguado, portanto, constituiu um limite da prática estilística de Mojica, relacionada ao som.

Além disso, Mojica também possuía outro motivo para utilizar a dublagem em seus filmes: ele sabia que sua dicção era ruim (o público tinha dificuldade de entender o que ele falava, problema que se acentuava nas mal equipadas salas de projeção brasileiras dos anos 1960) e tinha consciência de que falava um português trôpego, cheio de erros de gramática e concordância verbal. Assim, após concluir À meia-noite levarei sua alma, ele visitou os estúdios Odil Fono Brasil - empresa que fez, no começo dos anos 1960, toda a parte sonora dos filmes que ele dirigiu, incluindo as vozes e os ruídos - e passou alguns dias assistindo a filmes, a fim de escolher um dublador de cuja voz gostasse. Optou por Laércio Laurelli, que dublou Zé do Caixão em À meia-noite levarei sua alma, Esta noite encarnarei no teu cadáver e O estranho mundo de Zé do Caixão (BARCINSKI; FINOTTI, 1998, p. 108)

No fim da década de 1960, Mojica passou a finalizar a parte de som dos seus filmes na empresa AIC e foi forçado a mudar de dublador. Assim, Araken Saldanha fez o trabalho nos filmes Ritual dos sádicos, Finis hominis e Quando os deuses adormecem (1972), enquanto João Paulo Ramalho fez a voz do diretor em Exorcismo negro (1974) e Delírios de um anormal (1977). A voz real de Mojica só seria utilizada em filmes do diretor no longa-metragem Encarnação do demônio.

Por fim, a música utilizada nos filmes de Mojica também reflete fortemente o sistema de produção da Boca do Lixo. Ela era caracterizada pelo ecletismo, pela fusão despreocupada entre o erudito e o popular, funcionando como uma espécie de cadinho musical de um Brasil multicultural. Mojica usou música eletrônica de vanguarda (À meia-noite levarei sua alma), melodias de candomblé (O estranho mundo de Zé do Caixão), ópera (Perversão), música sacra (Esta noite encarnarei no teu cadáver), canções populares românticas, música orquestral de câmara (Finis hominis) e até trechos de programas radiofônicos.

\section{Conclusão}

Em uma das primeiras tentativas que fez para sintetizar seus apontamentos sobre o estilo cinematográfico em torno de um conceito estável, David Bordwell foi sucinto: "O estilo é o resultado de escolhas feitas pelo cineasta em circunstâncias históricas particulares" (BORDWELL, 1997, p. 4). Essa frase precisa ser desdobrada em um raciocínio mais complexo para dar conta da elasticidade do termo estilo. Quando se refere às "circunstâncias históricas particulares", Bordwell está se referindo à variada gama de limites e precondições imposta a qualquer cineasta por aspectos de natureza não estritamente cinematográfica, mas que remetem a contextos socioculturais, tecnológicos, econômicos, históricos, políticos e ideológicos nos quais ele opera.

2 O maior estúdio brasileiro dos anos 1950 durou quatro anos e produziu 22 longas-metragens. 
Todas as escolhas estilísticas e narrativas, mesmo as mais simples, são atravessadas por fatores não cinematográficos. Essas escolhas moldam a assinatura de um diretor, embora não sejam necessariamente pensadas de modo consciente. E poucas vezes essas escolhas são feitas livremente. A constituição do estilo se dá dentro de uma rede de contextos que se atravessam e incidem diretamente sobre essas escolhas. Orçamento, modas e censura, por exemplo, são alguns deles. Desse modo, os contextos devem ser considerados como um ponto de partida do processo de criação, uma espécie de tela em branco com limites definidos pelos fatores externos, e sobre a qual o artista opera suas escolhas narrativas e estilísticas.

Nesse ponto, Bordwell se apoia em Michael Baxandall (2005, p. 27), que enfatizou a necessidade de o pesquisador reconhecer a influência do entorno social do artista, quando tenta reconstituir as escolhas operadas por ele. Ao fazê-lo, o pesquisador ganha a clareza necessária para enxergar o artista (e sua cruzada em direção à constituição de um estilo) imerso dentro de uma rede de contextos. Só assim, avisa Baxandall, é possível validar o estudo do estilo: buscando não apenas a reconstituição dos resultados obtidos pelo artista, mas também a reconstituição de suas intenções.

Nesse sentido, a análise dos filmes em longa-metragem de José Mojica Marins revela um estilo próprio e uma assinatura estilística coerente. Esse estilo é representado por uma constelação de padrões recorrentes de forma e conteúdo, reconhecível quando se analisa os filmes inseridos nos contextos socioculturais, econômicos e tecnológicos em que eles foram realizados. A análise dos filmes de Mojica revela um cineasta que solucionou problemas de representação de modo consistente, lidando com os limites e precondições de trabalho inevitáveis a todo diretor sem perder a sintonia com o zeitgeist, com o ar de seu tempo - daí a aproximação inexorável que essa análise concretiza entre a obra de Mojica e os longas-metragens populares realizados dentro do sistema de produção de Cinecittà.

Sendo assim, esta análise reafirma a importância de Mojica como um autor original e inventivo no panorama do cinema de horror realizado na América Latina, pois mostra como ele antecipou tendências (como o uso de close-ups de rostos e a representação gráfica da violência) e manteve uma consistência estilística admirável ao longo de quase seis décadas de carreira.

Rodrigo Carreiro é professor do Programa de Pós-graduação em Comunicação (PPGCOM) e da graduação em Cinema e Audiovisual da UFPE; é doutor e em Comunicação pela UFPE.

rcarreiro@gmail.com 


\section{Referências}

BARCINSKI, André; FINOTTI, Ivan. Maldito: a vida e o cinema de José Mojica Marins, o Zé do Caixão. São Paulo: Editora 34, 1998.

BAXANDALL, Michael. Padrões de intenção: a explicação histórica dos quadros. São Paulo: Companhia das Letras, 2005.

BORDWELL, David. Figuras traçadas na luz. Campinas: Papirus Editora, 2009.

On the History of Film Style. London: Harvard University Press, 1997.

CÁNEPA, Laura Loguercio. Medo de quê: uma história do horror nos filmes brasileiros. (Tese de Doutorado). Universidade de Campinas, 2008.

COMPAGNON, Antoine. O demônio da teoria: literatura e senso comum. Belo Horizonte: Editora UFMG, 2010.

EISENSTEIN, Sergei. A forma do filme. Rio de Janeiro: Jorge Zahar, 1992.

GOMBRICH, E. H. Arte e ilusão: um estudo da psicologia da representação pictórica. São Paulo: Martins Fontes, 2007.

MOJICA, José. Entrevista. In: PUPPO, Eugênio (Org.). José Mojica Marins: 50 anos de carreira. São Paulo: Heco Produções, 2007.

PRIMATI, Carlos. O horror universal de Zé do Caixão. In: PUPPO, Eugênio (Org.). José Mojica Marins: 50 anos de carreira. São Paulo: Heco Produções, 2007.

REIS, Lúcio. A cultura do lixo: horror, sexo e exploração no cinema. (Dissertação de Mestrado). Universidade de Campinas, 2002.

SALT, Barry. Film Style \& Technology: History and Analysis. London: Stardword, 2009. 